\title{
A metamorfose nos contos fantásticos de Murilo Rubião
}

\author{
Luciane Alves Santos*
}

\begin{abstract}
Resumo: No Brasil, o universo ficcional de Murilo Rubião revela a importância de sua obra no âmbito da narrativa fantástica. Seus contos apontam, por meio do absurdo ficcional, a fatalidade da vida moderna, povoada de medo, angústia e solidão. A irrupção do fantástico apresenta-se nos contos do escritor mineiro, sobretudo, pelo processo de metamorfoses, que se desenvolve tanto pelos temas quanto pelo fazer poético. Dessa forma, a natureza fantástica de sua obra é também fruto de uma linguagem repleta de alegorias: linguagem que expõe as insatisfações humanas e assume caráter revelador e crítico.
\end{abstract}

Palavras-chave: conto fantástico; metamorfose; Murilo Rubião.

\begin{abstract}
In Brazil, the fictional universe of Murilo Rubião shows the importance of his work in the fantastic narrative space. Their short stories show, through fictional nonsense, the fatality of modern life, filled with fear, loneliness and anguish. The fantastic revelation appears in the stories of the writer from Minas Gerais especially through the metamorphosis process, that is showed by the subjects developed and the poetic language. This way, the fantastic nature of his work is also a result of the language full of allegories, which shows the human dissatisfaction and assumes a revealing and critical character.
\end{abstract}

Keywords: short story; fantastic; metamorphosis; Murilo Rubião.

\section{A constituição do cenário fantástico brasileiro}

Ao contrário das manifestações literárias hispano-americanas, que têm na literatura fantástica expressões como Borges, Arreola, Júlio Cortázar e Gabriel Garcia Márquez, o Brasil caminhou lentamente em direção ao gênero. No século XIX, a presença do fantástico se deu inicialmente no romantismo byroniano de Álvares de Azevedo. O autor escreveu o frenético Noite na Taverna (1855), uma coletânea que apresenta características bastante singulares. A obra narra um conjunto de episódios marcados por delírios, pela embriaguez, pelo crime e pelo deboche - tudo isso aliado à obsessão da morte, esta última, muito cultivada pelos românticos que a idealizaram como saída para seus impasses existenciais. O ponto de partida de Noite da Taverna é a reunião de personagens que se juntam para relatar fatos macabros que viveram ou que foram criados a partir da imaginação desses homens. Os protagonistas estão em estado de embriaguez, e narram experiências fantásticas e alucinantes. Tudo isso é regado à paixão carnal, criminosa ou incestuosa, sempre pervertida e no clima de

\footnotetext{
* Luciane Alves Santos professora de Teoria da Literatuta da UNESP - Faculdade Renascença/São Paulo. É também doutoranda do Departamento de Língua e Literatura Francesa da Universidade de São Paulo.
} 
total melancolia e obscuridade. Essas características são herança direta de uma tendência do romantismo europeu, que cultivou o frenético e as histórias de "arrepiar os cabelos".

Há também a obra de Machado de Assis, que apresenta algumas narrativas em que o fantástico se manifesta. O romance Memórias Póstumas de Brás Cubas (1881), por exemplo, representa um marco na literatura brasileira e, além de ser uma brilhante obra do Realismo brasileiro, pode, também, ser considerada como uma experiência do autor no campo do fantástico. Narrado por um defunto autor, ou um autor defunto - e aí está o elemento fantástico, que podemos ligar à sátira menipéia ou luciânica, uma forma de inverter o mundo que tem como referência os Diálogos dos Mortos, de Luciano de Samóstata -, o narrador passeia por sua vida, trazendo lembranças dela e fazendo análises corrosivas da sociedade de sua época. Uma vez rompidos os limites do possível, estamos no terreno do fantástico.

Embora muito tenham contribuído para a experiência do fantástico brasileiro, esses escritores, bem como outros, ainda estão distantes da concepção do fantástico contemporâneo, aquele que adentrou a literatura brasileira pela porta do século XX; é a partir do Modernismo que o Brasil se familiariza com o gênero.

Contemporaneamente, vários autores empregam o fantástico em suas obras de diferentes maneiras. Nilton Maciel (2001), em Literatura Fantástica no Brasil, buscou traçar um panorama do fantástico brasileiro; o autor reúne em seu artigo diversos críticos que, de alguma forma, descrevem e comentam a presença do gênero na literatura de nosso País. $O$ autor destaca Murilo Rubião, J.J. Veiga e Péricles Prade como os representantes legítimos da literatura fantástica brasileira.

Tanto em J.J. Veiga como em Murilo Rubião, a essência fantástica que carateriza suas obras é a alegoria. Entretanto, a constituição dos espaços difere. Em Murilo, o espaço é o cenário urbano moderno, a relação do homem com o caos gerado pelo progresso desumano das grandes cidades. Ao contrário do espaço urbano muriliano, o universo construído por J. J. Veiga revela-se, mais comumente, no espaço regional; o insólito flui da natureza, do contato do espírito humano com a terra, a água e o ar. Em Veiga, predominam as pequenas cidades; o fantástico surge do cotidiano e dos assuntos do homem da terra, do campo:

O fantástico de Murilo Rubião talvez seja mais intelectual. Os seus fantasmas são mais concebidos pelo espírito... Ao passo que os de Veiga são fornecidos pelo real, pelo folclore nacional, pelas crenças populares, já que as suas personagens são construídas de gente simples e humilde de nosso hinterland. Nesse sentido, os seus contos chegam a ser até regionalistas. Bastante brasileiros mesmo (LINHARES, 1973, p. 95).

Assim como na obra de Murilo, o fantástico de J.J. Veiga não apresenta fadas, fantasmas ou demônios; o que se revela é uma trama de situações dolorosas que conduz ao 
absurdo. A atmosfera que paira nos contos de Veiga é de opressão e desespero, fruto de uma tensão desencadeada pela alegoria que denuncia a violência física ou moral.

O terceiro nome apresentado por Maciel é Péricles Prade, escritor pouco conhecido nas letras brasileiras. Esquecido por alguns críticos e valorizado por outros, Péricles (também dedicado à poesia e ao ensaio) é o autor de duas obras que se situam no terreno do fantástico: Os milagres do Cão Jerônimo (1971) e Alçapão para Gigantes (1980).

O mundo fantástico construído por Péricles infiltra-se no cotidiano, transformado-o numa sobre-realidade; a conseqüência dessa intromissão é uma narrativa que desconcerta e destrói qualquer pretensão de manter o mundo intacto e equilibrado. Em muitos momentos falta-nos o chão, tudo gira em torno do absurdo e da secção do real através de imagens que passam a ter significado dentro da lógica textual.

De acordo com Fábio Lucas (1999), a introdução do sobrenatural na articulação temática cede à tentação de explorar os limites naturais, carregados de paixões, fraquezas e finitude, que presidem o universo humano. Assim como em Murilo, Péricles faz das imagens poderosos símbolos que remetem à reflexão da condição da existência.

\section{A palavra mágica de Murilo Rubião}

Murilo Eugênio Rubião nasceu em 1916 em Silvestre Ferraz, hoje Carmo de Minas (MG), tendo falecido em 1991 em Belo Horizonte, onde residiu a maior parte de sua vida. Foi escritor, advogado e jornalista.

$\mathrm{O}$ escritor começou a escrever bastante jovem. Com alguns colegas fundou a revista Tentativa, onde publicou seus primeiros trabalhos. Ainda bem moço, revelou uma grande visão crítica da realidade e sempre esteve engajado no movimento estudantil.

Murilo trabalhou em vários setores profissionais, em um de seus trabalhos dirigiu a rádio Inconfidência Mineira. Em 1942, formou-se em Direito e seguiu carreira burocrática no serviço público de Minas, com um intervalo de quatro anos na Área Federal, servindo o Brasil na Espanha. Longe de sua terra natal, sofreu o problema do exílio, pois não sabia o que era ser estrangeiro. Nesse período, escreveu Teleco, o coelhinho, um de seus mais publicados contos.

Uma de suas mais importantes conquistas foi a fundação do suplemento Literário de Minas Gerais, que teve grande apoio de renomados escritores, como Carlos Drummond de Andrade, Guimarães Rosa, Emílio Moura, Ciro dos Anjos, além de colaborações do estrangeiro. A sua obra de estréia, $O$ ex-mágico, foi lançada um ano depois de Sagarana, de 
Guimarães Rosa, ambos publicados pela Editora Universal e por interferência de Marques Rebelo. Esse primeiro livro de Rubião é recebido com bastante surpresa pelos críticos da época, o que se justifica pela opção literária do autor: o fantástico, afinal, nesse período, a literatura brasileira está marcada pela prosa de caráter regional.

A opção pelo fantástico teria sido herança da infância, das intermináveis leituras de contos de fadas, de Dom Quixote, da Bíblia Sagrada e das histórias das Mil e uma noites. O próprio Murilo afirmou que acreditava naquilo que estava além da rotina; assim, o sobrenatural e o mágico compõem a atmosfera onírica de seus contos.

$\mathrm{Na}$ obra de Murilo, percebe-se claramente os caminhos da narrativa, tudo aponta para a construção de uma situação absurda. Observe-se, por exemplo, a passagem abaixo, extraída do conto Teleco, o coelhinho.

— Moço, me dá um cigarro?

A voz era sumida, quase um sussurro. Permaneci na mesma posição em que me encontrava, frente ao mar, absorvido com ridículas lembranças.

O importuno pedinte insistia:

— Moço, oh! Moço! Moço, me dá um cigarro?

- Vá embora moleque, senão chamo a polícia.

— Está bem, moço. Não se zangue. E por favor, saia da minha frente, que eu também gosto de ver o mar.

Exasperou-me a insolência de quem assim me tratava e virei-me disposto a escorraçá-lo com um pontapé. Fui desarmado, entretanto. Diante de mim estava um coelhinho cinzento, a me interpelar delicadamente (RUBIÃO, 1998, p.143).

O exemplo acima pode ilustrar como o autor subverte a realidade a partir de uma situação banal e a transforma num acontecimento absurdo. Pode-se dizer que o real está presente; porém, desconhece os princípios lógicos e naturais que caracterizam o universo do racional. Não parece muito comum o fato de um coelhinho interpelar um homem e pedir-lhe um cigarro, no entanto, a realidade não foi abolida por completo: estamos diante de um espaço conhecido, com personagens vivendo em um mundo banal. O que o fantástico faz é subverter a ordem através de um acontecimento insólito. Eis, pois, a fantasia do real ou, mais precisamente, o fantástico, sob a forma do realismo mágico.

Nesse conto, como em outros do autor, surge uma realidade conturbada, produto do confronto razão/desrazão. Isso se dá porque a razão caminha em direção à desrazão, criando um universo insólito e absurdo. Assim, como afirma Bessière (1974), o discurso fantástico caracteriza-se pela antinomia real/irreal, que é a marca do contraste entre razão e desrazão. É essa antinomia que governa a obra muriliana. As fantásticas metamorfoses de Teleco estão inseridas em um mundo real e possível, porém duramente subvertido e arruinado pela implacável lógica do absurdo. 
A narrativa fantástica moderna questiona a razão, na medida que mostra a dura convivência do ser humano em um mundo que determinada cultura estabelece como normal, propagando um comportamento social que oprime e leva o homem às raias do absurdo.

Um dos aspectos que Todorov (1975) refutou em sua teoria da narrativa fantástica foi a presença de uma explicação alegórica para a existência do sobrenatural. Ora, que faz Murilo senão preencher seus contos de alegorias modernas? No conto $O$ ex-mágico da Taberna Minhota, o personagem é um mágico que tem o poder de transformar o mundo, de fazê-lo especial; porém, é incapaz de se adaptar a esse mundo, preferindo dedicar-se à própria morte. O seu fracasso diante da resolução de tirar a própria vida, depois de várias tentativas atrapalhadas, metamorfoseia-se numa grande alegoria da impotência do homem diante do mundo em que vive.

Ainda que Murilo Rubião afirmasse não ter recebido influências de Kafka, é impossível negar-lhe o parentesco temático; ambos compartilham a lógica do absurdo, a expressão máxima da opressão que leva o homem a um comportamento "estranho". Kafka e Murilo compõem em suas obras um mundo em que a realidade se apresenta de forma grotesca e alegórica; o homem é sufocado pelo seu cotidiano e a atmosfera pesada aponta para o absurdo, para o ilógico. Em Kafka, lemos: "Quando certa manhã Gregor Samsa despertou, depois de um sonho intranqüilo, achou-se em sua cama convertido em um monstruoso inseto" (KAFKA, 1998, p. 7). E em Teleco, o coelhinho, de Rubião: "Depois de uma convivência maior, descobri que a mania de metamorfosear-se em outros bichos era nele simples desejo de agradar ao próximo" (RUBIÃO, 1998, p. 144). Percebe-se que as metamorfoses não perturbam os personagens; o leitor pode sentir-se incomodado com os acontecimentos insólitos que os envolve, mas não os personagens.

Segundo Jorge Schwartz (1981), o fantástico se apresenta nos contos de Rubião como um artifício da imaginação para remeter a conflitos originários da própria realidade. Essa situação é lógica no fantástico, justamente porque nele a posição de irrealidade parte de uma motivação realista. Em todos os contos murilianos, o insólito e o estranho ocorrem no universo familiar e o cotidiano é abalado pela irrupção de um acontecimento desconhecido. Assim, conclui-se que o fantástico é, por natureza, antinômico, aliando sua irrealidade primeira a um realismo segundo. 


\section{Metamorfose: um processo literário}

O tema da metamorfose é bastante freqüente e antigo na literatura. Temos como exemplo a emblemática obra metamorfoses, do poeta latino Ovídio. Trata-se de um poema composto por quinze partes, que narram as diferentes transformações encontradas nos mitos. Na obra de Ovídio, não raramente, pessoas e deuses se metamorfoseiam em animais, plantas ou quaisquer outras formas. Além de ser encontrado nos relatos míticos, o tema da metamorfose surge nas diversas histórias que constituem a literatura infantil e a literatura contemporânea. A cada época, o tema recebeu tratamento diverso.

Na mitologia grega, desde Homero, a metamorfose sempre esteve associada à vontade própria do ser que se transmutava, ou a causas externas, como forma de punição ou prêmio. De acordo com Junito Brandão (1992), Proteu, na Odisséia, aparece como um deus marinho, encarregado de guardar os rebanhos de focas e de outros animais pertencentes a Poseidon. Seu habitat predileto era junto à ilha de Faros, não muito distante da foz do rio Nilo. Proteu recebeu o dom do conhecimento do passado, presente e futuro, mas não era fácil abordá-lo - e ele se recusava a utilizar seu dom com todos que vinham consultá-lo. Para escapar dos curiosos, ele tomava diferentes formas no intuito de afugentá-los: leão, tigre, dragão, leopardo, javali, e até mesmo de uma árvore ou do fogo. A única maneira de conseguir arrancar-lhe uma palavra era amarrando-o até que voltasse a sua forma primitiva.

Como na literatura clássica, a metamorfose se prestava ao objetivo de determinado fim: uma afronta ou um crime mereciam uma punição à altura da falta cometida. Medusa, uma das três górgonas, foi punida por ter ofendido a deusa Minerva. De beleza rara e cabelos magníficos, Medusa teve seus cabelos transformados em horríveis serpentes. Além disso, seus olhos foram dotados de poderosa força, capaz de petrificar todos aqueles que neles se fixavam.

A literatura do Maravilhoso é também rica em metamorfoses. A transformação, voluntária ou involuntária, povoa os contos de fadas. Na história $O$ rei sapo ou Henrique de Ferro, dos Irmãos Grimm, o príncipe encantado tem de passar por inúmeras provações e conquistar o amor de uma princesa. Só assim poderá ser libertado da maldição de viver com consciência humana, mas aprisionado sob a forma de um sapo. Nesse tipo de literatura, seres mágicos, como por exemplo, as bruxas, são dotados de poderes capazes de transformar a si mesmos e a outras pessoas em animais. Daí uma infinidade de bruxas que se metamorfoseiam em gatos, dragões ou aves, a fim de atingir os seus obscuros objetivos. Cabe ressaltar que, na 
literatura mítica e na literatura dos contos de fadas, a metamorfose sempre se manteve no plano físico.

Silva (1985) analisa a evolução desse tema durante os séculos. Segundo a autora, o tema da metamorfose nunca deixou de estar presente na literatura; da metamorfose física passou-se à retórica, pela utilização do símile e da metáfora. No Romantismo, as descrições dos personagens estão impregnadas de elementos metamórficos que se desenvolvem nas entrelinhas: os vilões desempenham papéis análogos a algumas características animais - lobos e serpentes, por exemplo. Às donzelas e aos heróis cabem as características nobres e dóceis do mundo animal.

Anos depois, no Naturalismo, a comparação se dá de forma inversa; o homem aparece em situação de regresso à animalidade. Essa regressão é impulsionada pela força do instinto e pela opressão do meio social. Decorre disso uma nova forma de metamorfose: aquela que não se dá no plano físico, e sim nas esferas do comportamento humano e de suas relações com a sociedade.

No folclore brasileiro, a metamorfose é uma constante; expressões como a mula-semcabeça, o lobisomem e outros seres mágicos encontram seu significado no imaginário coletivo, que alimenta suas existências, pois são as lendas e mitos de um povo que os mantêm vivos. O lobisomem, por exemplo, apresenta-se na mitologia brasileira como um homem que se metamorfoseia num ser coberto de pêlos, possuidor de olhos vermelhos e aterrorizantes. Figuras como essa, ainda muito presentes na cultura popular, estão longe das metamorfoses que ocorrem na obra de Murilo Rubião. No universo ficcional muriliano não estamos diante de um espaço regional povoado de mitos e lendas; o espaço escolhido pelo autor é o espaço urbano moderno, aquele que comporta todos os problemas da dita civilização: marginalização, medos, violência, burocracia e desamores. É dentro desse espaço e dessa disposição para a vida que brota o fantástico.

Em seus contos, o tema da metamorfose remete à problemática existencial: o sentido da vida. São as dúvidas, o mistério, o absurdo e o vazio sufocante que constituem a literatura fantástica do nosso século, literatura essa que encontra em Murilo Rubião sua maior expressão.

Muitos personagens murilianos fogem; não apenas dos outros, mas, muitas vezes, de si mesmos, de sua própria história de vida, e o elemento mágico que os transcende é também a metamorfose.

O processo de metamorfose encontra na obra de Murilo diversos caminhos: o processo de reescritura dos contos - alguns foram reescritos mais de três vezes -, a transformação dos 
seres em busca de uma acomodação no espaço em que vivem, o mágico desdobramento das epígrafes e a alegoria que sustenta o texto em sua dimensão trágica.

Silva avalia que, contemporaneamente, a metamorfose acarreta um sentido de melhora e, às vezes, de degradação. Dadas as condições do mundo moderno, acreditamos que as metamorfoses são instrumentos que revelam pessimismo e impossibilidade de adaptação à modernidade; portanto, as transformações geram a degradação do homem que busca desesperadamente uma maneira de fugir de sua própria condição.

\section{Teleco, o coelhinho - A vida multiplicada}

Os contos de Murilo Rubião se situam em uma época em que a explicação racional dos fatos e a explicação divina caíram em descrédito. A ciência e a razão entraram em crise e não suportam mais o peso da condição humana; tantos fatos cotidianos parecem ser inexplicáveis, que a literatura fantástica abraçou esse conflito traduzindo em símbolos e alegorias a incapacidade científica, ou religiosa, de explicar a existência humana e a suas mazelas.

O tema da metamorfose, que tão bem serviu - e serve - à literatura fantástica, pode ser encontrado, como já foi apontado, de uma forma ou de outra, na maioria dos contos do escritor mineiro. O conto Teleco, o coelhinho expõe o difícil convívio entre um homem solitário e um coelho que, constantemente, metamorfoseia-se em outros animais. Teleco encontra uma mulher sedutora e se apaixona. Para viver esse romance e afirmar-se como homem, o coelhinho assume a forma de um canguru com um comportamento humano, porém degradante. A relação entre o protagonista e o canguru torna-se tensa, levando à expulsão do animal, que passa a viver com a namorada, que explora o seu dom. Após a decepção amorosa, Teleco volta para o seu amigo, arrependido, doente e pede ajuda. Não tarda para que Teleco consiga sua última e desejada metamorfose: uma criança, ainda que sem vida.

O processo de metamorfoses desencadeado no conto, além da busca de identidade, é impulsionado pelo desejo de agradar os outros, e segue uma lógica narrativa que garante ao texto a verossimilhança interna:

\footnotetext{
Mais importante é a verossimilhança interna, a coerência estrutural da obra, porque, quanto à verossimilhança externa, a fuga para o fantástico, para o mundo da imaginação, é comum à literatura. Transformar um homem em animal ( $O$ asno de ouro, de Apuleio) ou em inseto ( $A$ metamorfose, de Kafka) e conferir a esses seres não-humanos inteligência e sentimentos fazem parte do heterocosmo poético, cujas leis podem ser homólogas, no máximo, mas nunca idênticas às do mundo real (cf. ONOFRE, 2000, p. 35).
} 
De acordo com Vax (1965), o elemento fantástico contrasta com a realidade cotidiana, pois é o mundo inteiro que oscila no fantástico. No conto, o fantástico surge de um elemento ingênuo: um simples coelhinho de dimensão humana e dramática revela ao homem a verdade que ele não pode suportar: o homem contemporâneo é massificado, sem identidade e solitário.

O cotidiano apresentado no conto é absolutamente fiel ao nosso mundo real; a partir da presença de um coelhinho, que busca a sua humanidade, temos a subversão desse real harmônico. A princípio, Teleco encontra nas metamorfoses a maneira de se aproximar do humano, afinal, ele é um ser marginalizado, um ser que ninguém reconhece como humano e que busca a todo custo sua aceitação: "Depois de uma convivência maior, descobri que a mania de metamorfosear-se em outros bichos era nele simples desejo de agradar ao próximo" (RUBIÃO, 1998, p.144).

Além de agradar os outros, Teleco busca incessantemente uma forma de adaptação ao mundo que lhe é negado pelo desprezo e indiferença dos homens. A mania de se metamorfosear é uma busca angustiada de se encontrar ou libertar-se do mundo que o oprime. Em sua ânsia pelo reconhecimento, Teleco metamorfoseia-se num asqueroso canguru; essa metamorfose funciona com um espelho do comportamento humano, afinal, o que Teleco deseja é comportar-se como homem.

As marcas que denunciam o conflito da busca da humanidade servem de ferramenta para a composição da atmosfera onírica. À medida que essa busca se adensa, a metamorfose condiciona o sujeito a uma imagem deformada do objeto de desejo. O querer desenfreado de Teleco constrói um muro entre a realidade que o cerca e o que ele julga como real. A sua condição de coelho é que o faz não-humano; logo, a metamorfose em canguru livra-o da forma anterior, tornando-o, conseqüentemente, humano. Barbosa é um homem (canguru) e não um coelho, por isso usa óculos e cospe no chão. A meiguice do coelhinho cede à bruta imagem, cheia de vícios, do horrendo canguru:

Barbosa tinha hábitos horríveis. Amiúde cuspia no chão e raramente tomava banho, não obstante a extrema vaidade que o impelia a ficar horas e horas diante do espelho. Utilizava-se do meu aparelho de barbear, de minha escova de dentes e pouco serviu comprar-lhe esses objetos, pois continuou a usar os meus e os dele. [...] Também a sua figura tosca me repugnava. A pele era gordurosa, os membros curtos, a alma dissimulada. Não media esforços para me agradar, contando-me anedotas sem graça, exagerando nos elogios à minha pessoa (RUBIÃO, 1998, p.148).

O diminutivo afetuoso, que nos é dado logo no início do conto, caracteriza a imagem doce do animal que gostava de ser gentil com crianças e velhos, divertindo-os com seu dom; porém a autodenominação Antônio Barbosa é o traço distintivo entre o homem que ele afirma 
ser e o animal que não mais existe. "Teleco?! Meu nome é Barbosa, Antônio Barbosa, não é, Tereza?" (RUBIÃO, 1998, p. 148)

Enquanto Teleco era apenas um coelhinho que divertia e preenchia o cotidiano solitário do narrador, nada de errado havia em suas metamorfoses. O ponto desestruturador do equilíbrio parte de sua obstinação em se afirmar como homem e, conseqüentemente, da ameaça que representava para a vida estéril do narrador. Enquanto Teleco lutava para libertarse e subverter um mundo organizado para nele adentrar, o narrador se esforçava para mantê-lo intacto.

Os opostos que representam a condição de existência do coelhinho e o objeto do desejo - inumano/humano - configuram a síntese na qual o duplo se manifesta, promovendo o conflito entre esses seres. Essa batalha simbólica tece a rede da composição de um mundo que aponta, invariavelmente, para a exclusão de um desses seres.

Em diversas ocasiões, apelei para a sua frouxa sensibilidade, pedindo-lhe que voltasse a ser coelho.

— Voltar a ser coelho? Nunca fui bicho. Nem sei de quem você fala.

- Falo de um coelhinho cinzento e meigo, que costumava se transformar em outros animais (RUBIÃO, 1998, p.149).

O poder de metamorfose, que ajudava Teleco em sua convivência com o narrador, é revertido a partir do momento em que tenta obstinadamente conhecer o comportamento humano e o amor. Agora, metamorfoseado em canguru, Teleco é o alvo da ira de seu companheiro. Nos contos de fada, o poder mágico é o diferencial dos personagens, pois aquele que tem a magia tem o poder ao seu lado. Com Teleco temos o oposto: a magia da metamorfose não pode libertá-lo, nem dar a ele poderes ilimitados, como, por exemplo, a tão desejada forma humana. Nem mesmo a mágica pôde libertá-lo da impotência diante do mundo mecanizado, da solidão e da tristeza.

Existir na forma de coelho não o satisfazia, ele precisava ser reconhecido como homem e, para isso, buscou uma aliada: a namorada Tereza. A namorada estabelece com Teleco uma relação de troca: enquanto Teleco lhe satisfaz os desejos e garante sua estabilidade financeira, ela o reconhece como homem. Esse acordo desonesto leva-o ao desespero e à frustração. Cansado e doente, desiludido com a falsa realidade que buscara na companheira, retorna à casa de seu amigo, onde ambos compartilham a impotência diante da fatalidade:

Teleco se lamuriava, transformando-se seguidamente em animais os mais variados. Gaguejava muito e não podia alimentar-se, pois a boca, crescendo e diminuindo, conforme o bicho que encarnava na hora, nem sempre combinava com o tamanho do alimento. Dos seus olhos, então, escorriam lágrimas que, pequenas nos olhos miúdos de um rato, ficavam enormes na face de um hipopótamo. 
Ante minha impotência de diminuir-lhe o sofrimento, abraçava-me a ele, chorando (RUBIÃO, 1998, p.152).

O desequilíbrio das metamorfoses de Teleco é a representação máxima de seu descontrole emocional, de sua frustração diante do desejo de tornar-se homem. A solidariedade no narrador presta-se a consolidar sua impotência diante de sua impossibilidade existencial. Animal e homem são um só e, também, não são ninguém, nada, perante o mundo mecanizado e frio. As lágrimas que ora surgem mínimas, ora imensas, dadas as proporções dos animais em questão, apontam para uma situação absurda que prenuncia uma condição exclusivamente humana: Teleco caminha para a realização de seu obscuro desejo.

A meiguice do coelhinho é perdida mediante a imposição da metamorfose em canguru; em seguida vem a sua derradeira metamorfose e a realização do desejo, porém um desejo que o destitui da vida: "Ao acordar, percebi que uma coisa se transformara nos meus braços. No meu colo estava uma criança encardida, sem dentes. Morta” (RUBIÃO, 1998, p. 152).

Geralmente, o nascimento de uma criança significa a intensidade da vida, a promessa de um novo tempo. Teleco assume, fisicamente, a forma humana; porém, falta-lhe a integridade do espírito, falta-lhe a condição de viver. Encontramos no final do conto uma dupla transformação, que envolve simultaneamente a degradação física e a espiritual. Para os seres deslocados no tempo e no espaço - aqueles que tem o querer, mas não o poder - não há novos tempos.

Ao relativizar o real, o fantástico está presente na busca de um sentido para a existência. Assim, a morte do coelhinho e sua última metamorfose caracterizam não o sobrenatural, mas a desrazão existente no centro das relações humanas. O mundo externo segue a perfeita caracterização do real; o mundo interior se manifesta pela irracionalidade, pela luta desesperada do ser na busca de uma identidade, de uma explicação lógica para a sua existência no conturbado mundo moderno.

Dessa forma, o fantástico irrompe por meio do descompasso do progresso tecnológico em relação ao homem. Temos o espectro que vaga na modernidade, no conturbado meio urbano, mas em uma nação periférica e atrasada, onde o presente será sempre o passado.

A opção do fantástico na obra muriliana se revela instrumento de crítica. A intenção do autor é a denúncia do absurdo da existência perante a destruição do que se tem de mais valoroso - a individualidade. Seus contos não se propõem a responder ou resolver as questões do mundo, ao contrário, são enigmas que conduzem à reflexão do real. O que o autor busca é o espelhamento de um mundo caótico, regido pela causalidade, dominado pelo absurdo das 
situações insólitas, que aponta para a crescente desumanização e degradação do homem. Nessa perspectiva, a narrativa fantástica serviu e serve como instrumento que acentua o horror, o universo às avessas regido pelas leis da dura realidade.

\section{Referências}

ALTER, Robert; KERMOND, Frank (Orgs.). Guia literário da Bíblia. Tradução de Raul Fiker. São Paulo: Unesp, 1997.

ARRIGUCCI JÚNIOR, Davi.O mágico desencantado ou as metamorfoses de Murilo. In: RUBIÃO, Murilo. O pirotécnico Zacarias. São Paulo: Ática, 1981.

ARRIGUCCI Júnior, Davi. Minas, assombros e anedotas (Os contos fantásticos de Murilo Rubião). In: Enigma e comentário: ensaios sobre literatura e experiência. São Paulo: Companhia das Letras, 1987.

ASSIS, Machado de. Obras completas. Rio de Janeiro: Aguilar, 1971.

BESSIÈRE, Irène. Le récit fantastique. Paris: Larousse, 1974.

BÍBLIA SAGRADA, Velho Testamento e Novo Testamento. Tradução de Ivo Storniolo e Euclides Martins Balancin. 2. imp. Rio de Janeiro: Imprensa Bíblica Brasileira, 1972.

BRADBURY, Malcom; McFARLANE, James. Modernismo - guia geral. Tradução de Denise Bottmann. São Paulo: Companhia das Letras, 1998.

BRANDÃO, Junito. Dicionário Mítico Etimológico. Rio de Janeiro: Vozes, 1992. vol. II.

CARPENTIER, Alejo. A literatura do maravilhoso. São Paulo: Vértice, 1987.

CHIAMPI, Irlemar. O realismo maravilhoso. São Paulo: Perspectiva, 1980. (Coleção Debates)

EHRSAM, Véronique; EHRSAM, Jean. La littérature fantastique en France. Paris: Hatier, 1985 .

FINNÉ, Jacques. La littérature fantastique. Bruxelles: Université de Bruxelles, 1980.

GOULART, Audemaro. O conto fantástico de Murilo Rubião. Belo Horizonte: Editora Lê, 1995.

GREGOLIN, Maria do Rosário. Mistério e Esterilidade.1993. Dissertação (Mestrado em Letras / Lingüística) - Unicamp, Campinas, 1993.

HANSEN, João Adolfo. Alegoria - construção e interpretação da metáfora. São Paulo: Atual, 1986. 
KAFKA, Franz. A metamorfose. Tradução e posfácio de Modesto Carone. São Paulo: Companhia das Letras, 1997.

$\mathrm{KOCH}$, Émile. Contribuição para o estudo do fantástico no romance. Lisboa: Tipografia Gaspar, 1957, p. 25 - 223.

LINHARES, Temístocles. 22 Diálogos sobre o Conto Brasileiro Atual. Rio de Janeiro: José Olympio /Conselho Estadual de Cultura de São Paulo, 1973

LINS, Álvaro. Sagas de Minas Gerais. In: Os mortos de Sobressaca. Rio de Janeiro: Civilização Brasileira, 1963.

LUCAS, Fábio. Os gigantes aprisionados de Péricles Prade. In: PRADE, Péricles. Alçapão para gigantes. Santa Catarina: Letras Contemporâneas, 1996.

MACIEL, Nilton. Literatura Fantástica no Brasil (esboço histórico). Disponível em: http://www.usinadeletras.com.br/exibelotexto.phtml?cod=1799\&cat=Ensaios - Acesso em: 20 dez. 2002.

MOLINO, Jean. Le fantastique entre l'oral et l'écrit. Europe: Les fantastiques, n. 611, p. 3$122,1980$.

ONOFRE, Salvatore. Teoria do texto. São Paulo: Ática, 2000.

PAES, José Paulo (Org. e Trad.) Os buracos da máscara. Antologia de contos fantásticos. São Paulo: Brasiliense, 1985.

PRADE, Péricles. Alçapão para gigantes. Santa Catarina: Letras Contemporâneas, 1996.

ROCHA, Hildon. Álvares de Azevedo: Anjo e demônio do Romantismo. Rio de Janeiro: José Olympio, 1982.

RODRIGUES, Selma. O fantástico. São Paulo: Ática, 1988. (Coleção Princípios)

RUBIÃO, Murilo. Contos reunidos. São Paulo: Ática, 1998

SCHWARTZ, Jorge. (Org.) Literatura Comentada - Murilo Rubião. São Paulo: Abril, 1982. . Murilo Rubião: a poética do Uroboro. São Paulo: Ática, 1981.

SILVA, Vera Maria. A metamorfose nos contos de Lygia Fagundes Telles. Rio de Janeiro: Presença Edições, 1985.

SPLINLER, William. Magic realism: a typology. Forum for modern language studies. Oxford, 29-1, p. 75-81, 1993.

TODOROV, Tzvetan. Introdução à literatura fantástica. Tradução de Maria Clara Correa Castello. São Paulo: Perspectiva, 1975. 
VAX, Louis. A arte e a literatura fantásticas. Tradução de J. Costa. Lisboa: Arcádia, 1972. (Biblioteca Arcádia de Bolso)

VAX, Louis. La séduction de l'étrange. Paris: PUF, 1965.

ZAGURY, Eliane. Murilo Rubião, o contista do absurdo. In: . A palavra e os Ecos. Rio de Janeiro: Vozes, 1971. 